\title{
Failure Analysis of T-38 Aircraft Burst Hydraulic Aileron Return Line
}

\author{
J. E. Martinez ${ }^{1}$, J. D. Figert ${ }^{1}$, R.M. Paton ${ }^{1}$, S.D. Nguyen $^{2}$, A. Flint ${ }^{2}$ \\ ${ }^{1}$ Materials \& Processes Branch, MC: ES4, Structural Engineering Division \\ ${ }^{2}$ Flight Systems Engineering Branch, MC: CC331, Aircraft Operations Division \\ National Aeronautics and Space Administration, Lyndon B. Johnson Space Center \\ 2101 NASA Parkway Houston, TX 77058
}

During maintenance troubleshooting for fluctuating hydraulic pressures, a technician found that a right hand aileron return line, on the flight hydraulic side, was ruptured (Fig. 1,2). This tubing is part of the Hydraulic Flight Control Aileron Return Reducer to Aileron Manifold and is suspected to be original to the T-38 Talon trainer aircraft. Ailerons are small hinged sections on the outboard portion of a wing used to generate rolling motion thereby banking the aircraft. The ailerons work by changing the effective shape of the airfoil of the outer portion of the wing [1]. The drawing, Northrop P/N 3-43033-55 (6/1960), specifies that the line is made from 0.375 inch OD, aluminum 5052-0 tubing with a 0.049 inch wall thickness. WW-T-787 requires the tube shall be seamless and uniform in quality and temper [2]. The test pressure for this line is $3000 \mathrm{psi}$, and the operational pressure for this line is estimated to be between $45 \mathrm{psi}$ and $1500 \mathrm{psi}$ based on dynamic loading during flight.

Examination of the fracture surface found evidence of arrest bands originating on the inner diameter (Fig 3). Ductile dimples are observed on the tube fractures (Fig. 4). The etched cross-section revealed thinning and work-hardening in the burst region (Fig. 5). The wall thickness just outside the work-hardened fracture region measured 0.035 ".

Barlow's Formula: $\mathbf{P}=2 \mathrm{St} / \mathrm{D}$, where $\mathbf{P}$ is burst pressure, $\mathbf{S}$ is allowable stress, $\mathbf{t}$ is wall thickness and $\mathbf{D}$ is the outer diameter of tube. Using the ultimate tensile strength of $28 \mathrm{ksi}$ and a measured wall thickness of 0.035 inches at burst, $\mathbf{P}=\mathbf{5 . 2} \mathbf{~ k s i}$ (burst pressure). Using the yield of $13 \mathrm{ksi}$ (YS) for aluminum 5052-0, plastic deformation will happen at $\mathbf{P}=\mathbf{2 . 4}$ ksi suggesting plastic deformation occurred at a proof pressure of $3.0 \mathrm{ksi}$.

Conclusion:

The burst resulted from high stress, low-cycle fatigue.

- Evidence of arrest bands originating on the inner diameter.

- Fracture is predominately shear dimples, characteristic of high load ductile fractures (Fig 6).

- Section wall reduction in the burst region.

- Plastic deformation and thinning of the out-of-specification tube wall likely happened during the initial proof testing years ago.

- Metallography of tubing away from rupture site confirmed tubing was seamless.

Based on the tube microstructure, it is likely that the initial wall thickness was about $30 \%$ thinner than the requirement of 0.049 inches. Fracture initiated on the ID and progressed to the OD (shear lip). The tube is made of the correct material of 5052-0 aluminum as verified using Optical Emission Spectroscopy (Table 2). The tubing hardness tested 77 HV100 (77 HRE). This hardness is slightly above the requirement for $70 \mathrm{HRE}$ maximum for aluminum 5052-0 in AMS 2658C [3]. 


\section{References}

[1] http://www.grc.nasa.gov/WWW/K-12/airplane/alr.html [2] Air Force WW-T-787B Canc: Tube, Aluminum Alloy, Round, Square, Rectangular, and Other Shapes, Drawn, Seamless, 5052

\section{[3] SAE AMS2658C: Hardness and Conductivity Inspection of Wrought Aluminum Alloy Parts}

\begin{tabular}{|c|c|c|c|}
\hline Wall Thickness Req. & Near Failure & Failed Tube Away from Failure & Replacement Tubing \\
\hline 0.049 Inch & 0.039 Inch & 0.045 Inch & 0.053 Inch \\
\hline
\end{tabular}

Table 1. Dimensional Analysis of Wall Thickness

\begin{tabular}{|c|c|c|}
\hline \multicolumn{2}{|c|}{ WW-T-787b Chemical Composition Requirements } & Optical Emission Spectroscopy Test Results \\
\hline Element & $\underline{\text { Percent }}$ & Percent \\
\hline Magnesium & $2.2-2.8 \%$ & $2.24 \%$ \\
\hline Chromium & $0.15-0.35 \%$ & $0.21 \%$ \\
\hline Iron plus Silicon & $0.0-0.45 \%$ & $0.29 \%$ \\
\hline Manganese & $0.0-0.10 \%$ & $0.01 \%$ \\
\hline Copper & $0.0-0.10 \%$ & $0.03 \%$ \\
\hline Zinc & $0.0-0.10 \%$ & $0.01 \%$ \\
\hline Aluminum & Remainder & $96.39 \%$ \\
\hline
\end{tabular}

Table 2. Optical Emission Spectroscopy (OES)

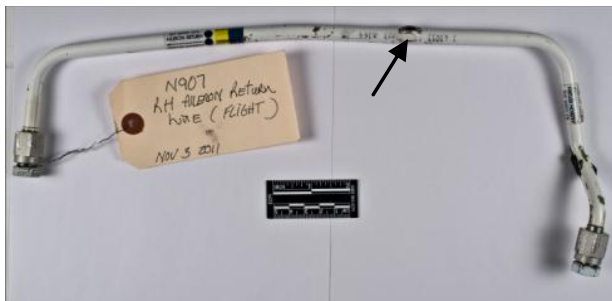

Fig 1. The as-received tube from the T-38 (N907) hydraulic flight control aileron return reducer to aileron manifold exhibits a burst at the arrow location.

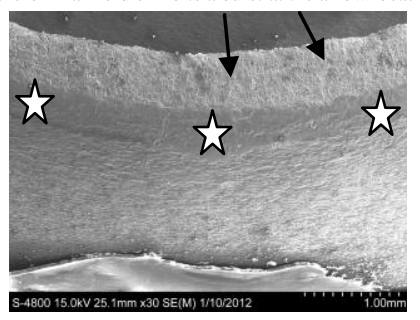

Fig 3. SEM micrograph of fracture surface exhibiting crack arrest bands (arrows) originating on the tube ID. The multiple site arrest bands are semi-circular in shape with the radii originating in the center of the tube. A shear lip (stars) is noted on the tube OD.

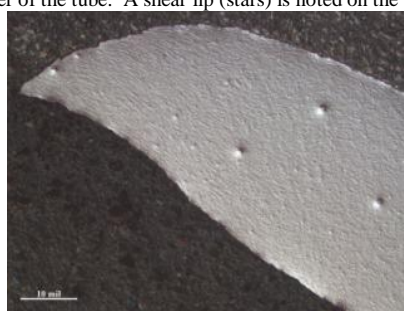

Fig 5. Cross section of fracture as-etched (Barkers) showing wall reduction and elongated grains.
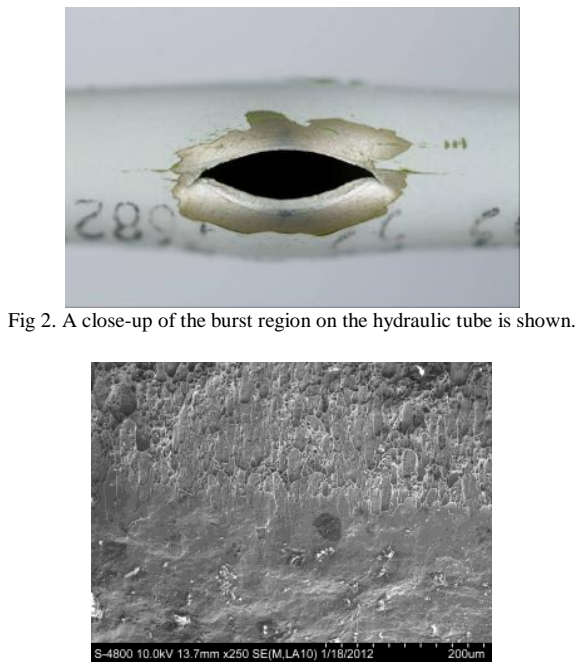

Fig 4. SEM micrograph of fracture surface exhibiting mostly U-shaped shear dimples.

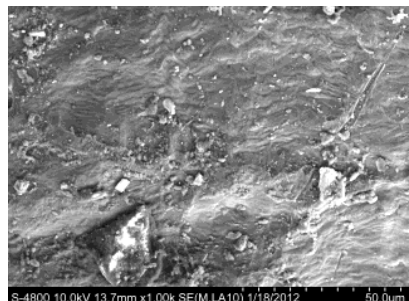

Fig 6. SEM micrograph of fracture at ID demonstrating low cycle fatigue striations. 
Microscopy \& Microanalysis 2012

Symposium P06 - Failure Analysis of Structural Matterials

Failure Investigation of 3 s. Burst Hydraulic Aileroñ Return Line

J.E. Martinez ${ }^{1}$, J.D. Figert ${ }^{1}$, R.M. Patin ${ }^{1}$, S.D. Nguyen ${ }^{2}$, 1.F. Fint ${ }^{2}$,

${ }_{1}$ Structural Engineering Division

${ }^{2}$ Aircraft Operations Division

Lyndon B. Johnson Space Center Houston, TX 77058
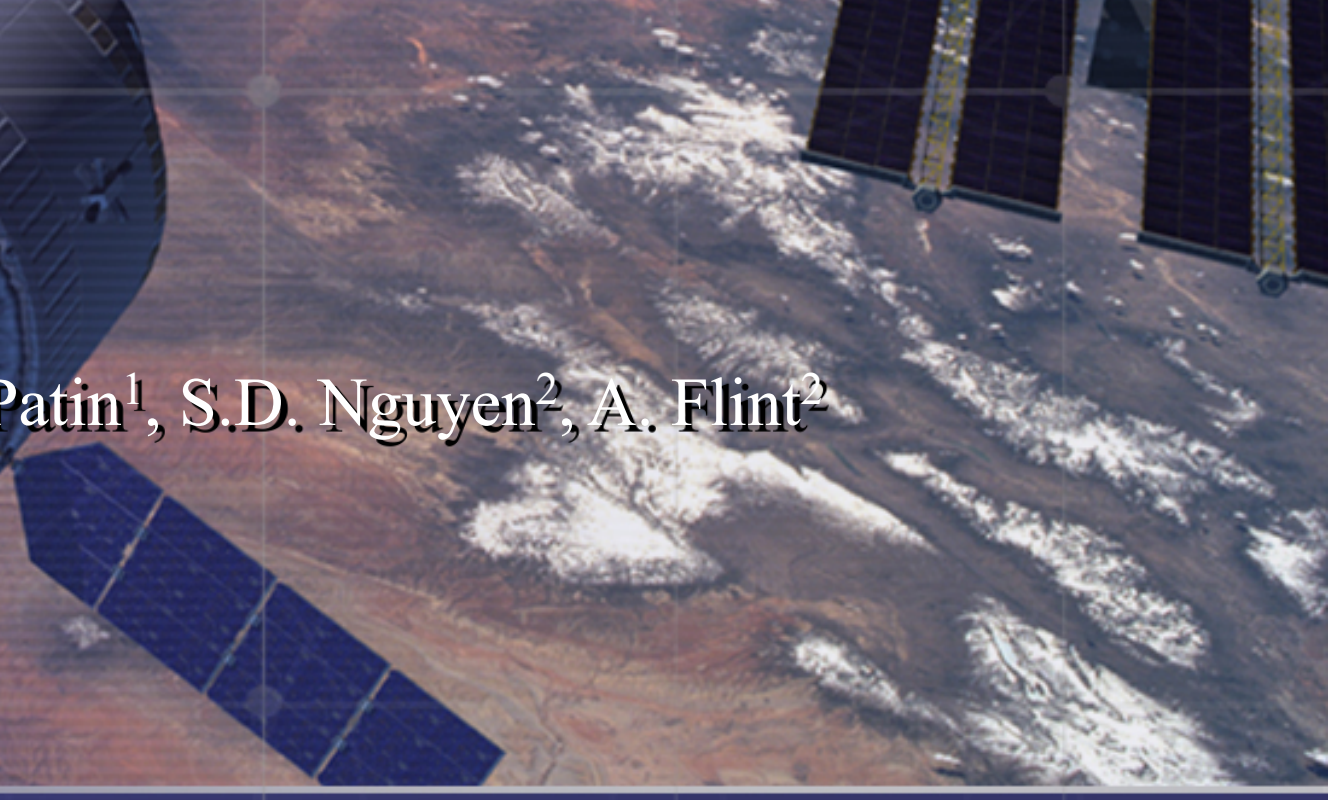


\section{T-38. Aircraft General Characteristics:}
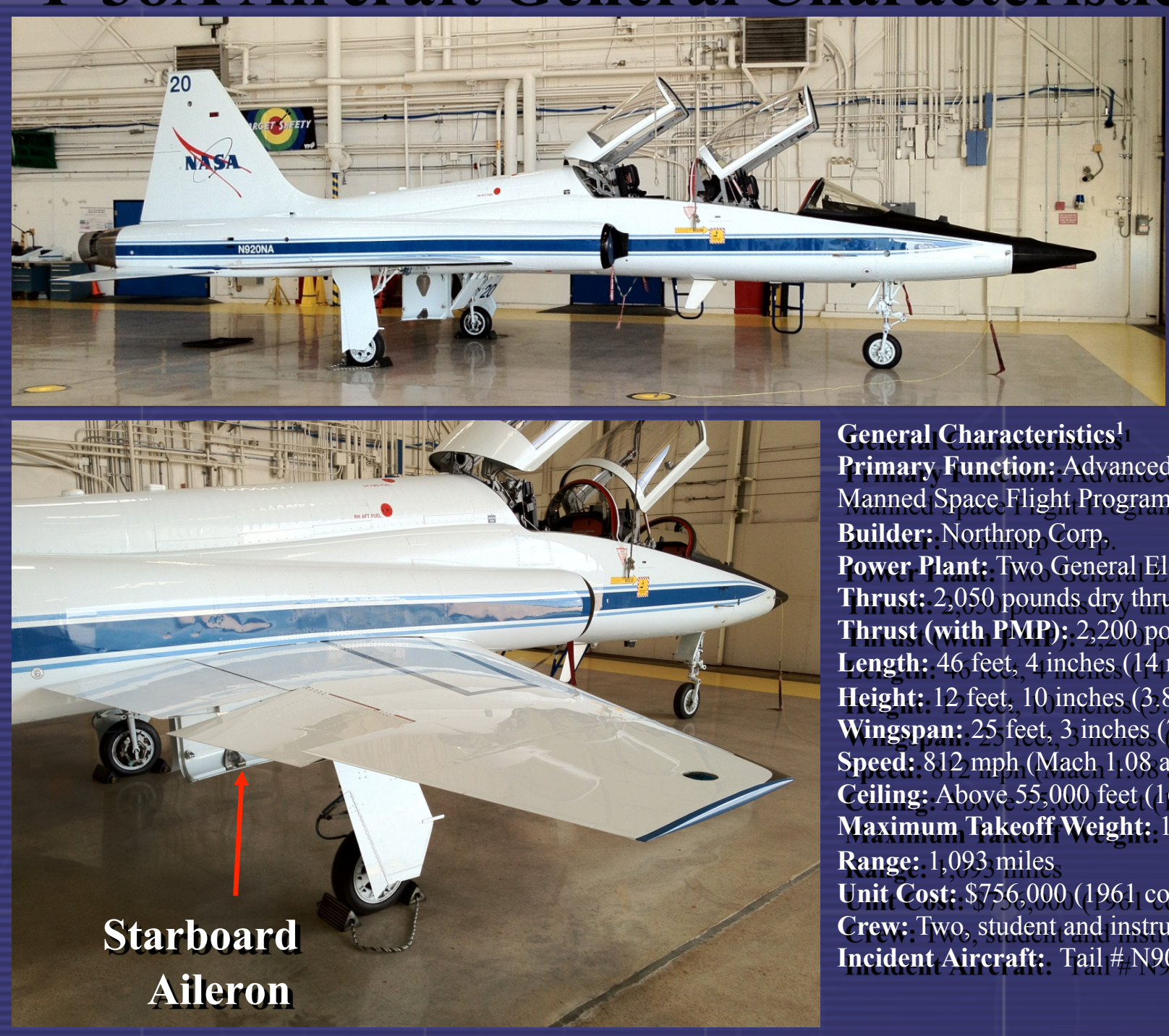

General/Characteristics 1

Primary Function: Advanced jet pilot trainer for Astronauts and as chase plane for Manned Space.Flight Programs.

Builder: Northrop Corp

Power Plant: Two General Electric J85-GE-5-turbojet engines with afterburnerss

Thrust: 2,050 pounds dry thrust, $2,2,900$ with afterburners

Thrust (with PMP): 2, 200 pounds dry thrust; 3,300 with afterburners Length: 46 feet, 4 inches ( 14 meters)

Height: 12 feet, 10 inches ( 3.8 meters)

Wingspan: 25 feet, 33 inches $(7,6$ meters $)$

Speed: $8122 \mathrm{mph}_{1}$ (Mach 1.08 at sea level)

Ceiling: Above 55,000 feet (16,764 meters)

Maximum Takeoff Weight: 12,093 pounds (5,485-kilograms)

Range: 1,093 miles

Unit Cost: $\$ 756,000$ (1961 constant dollars)

Crew: Two, student and instructor

Incident Aircraft: Tail \#N907 


\section{Background:}

During a Functional Check Flight (FCF), the pilot observed fluttered movement on the flight system hydraulic pressure indicator.

Hydraulic power is supplied by two systems ${ }^{2}$ :

The utility system \& the flight control system.

Each system is powered by a piston-type engine-driven pump. The left engine drives the utility system pump and the right engine drives the flight control system pump.

They two systems are identical in operation and provide redundancy in the event either system should fail.

Both systems operate at 3,000 PSII. All hydraulic pressure lines are corrosion resistant steel. Return and suction rigid lines are aluminum alloy, except in landing gear wheel wells and aft of engine firewall.

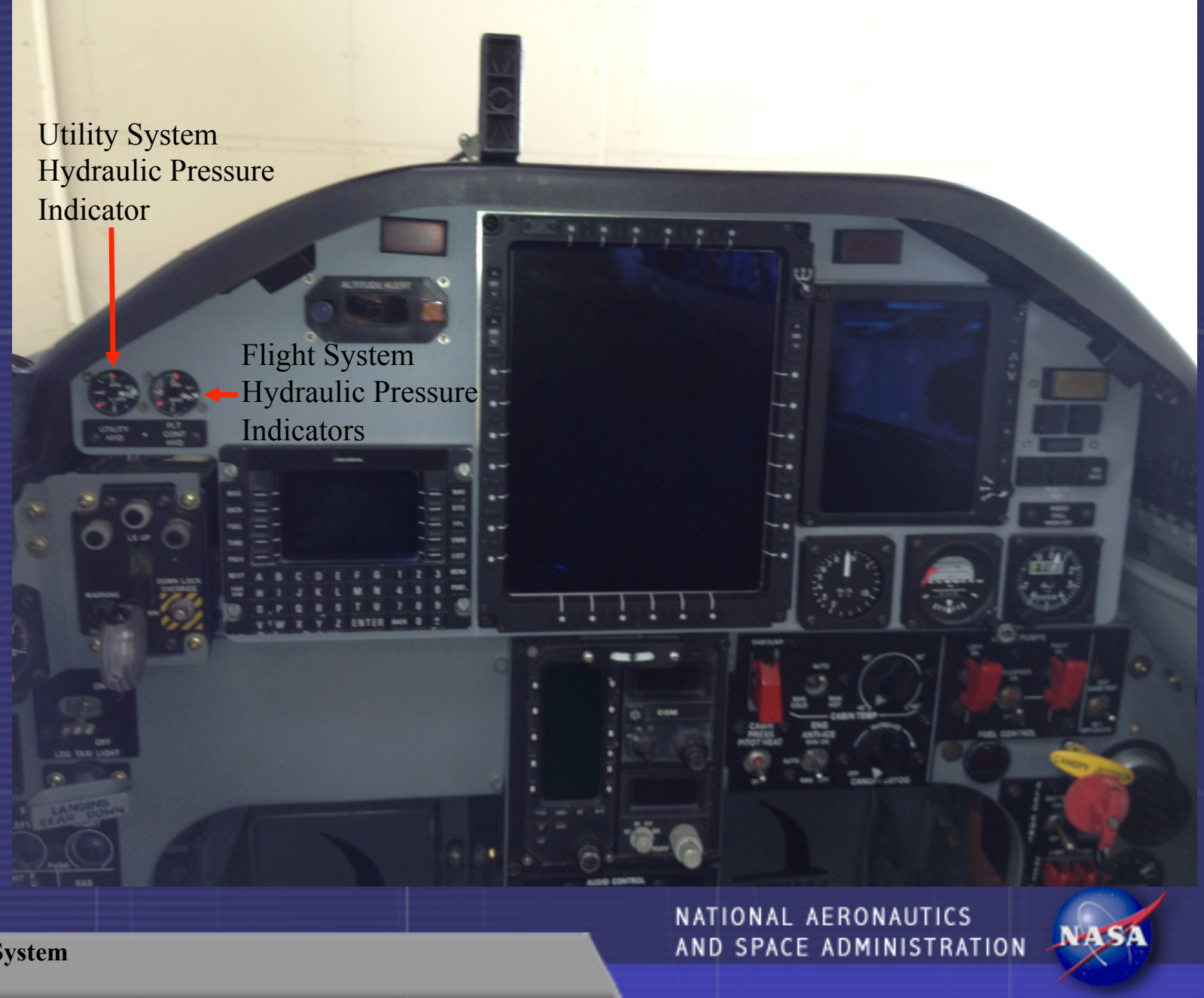




\section{Alleron Alctuating Cylinder:}

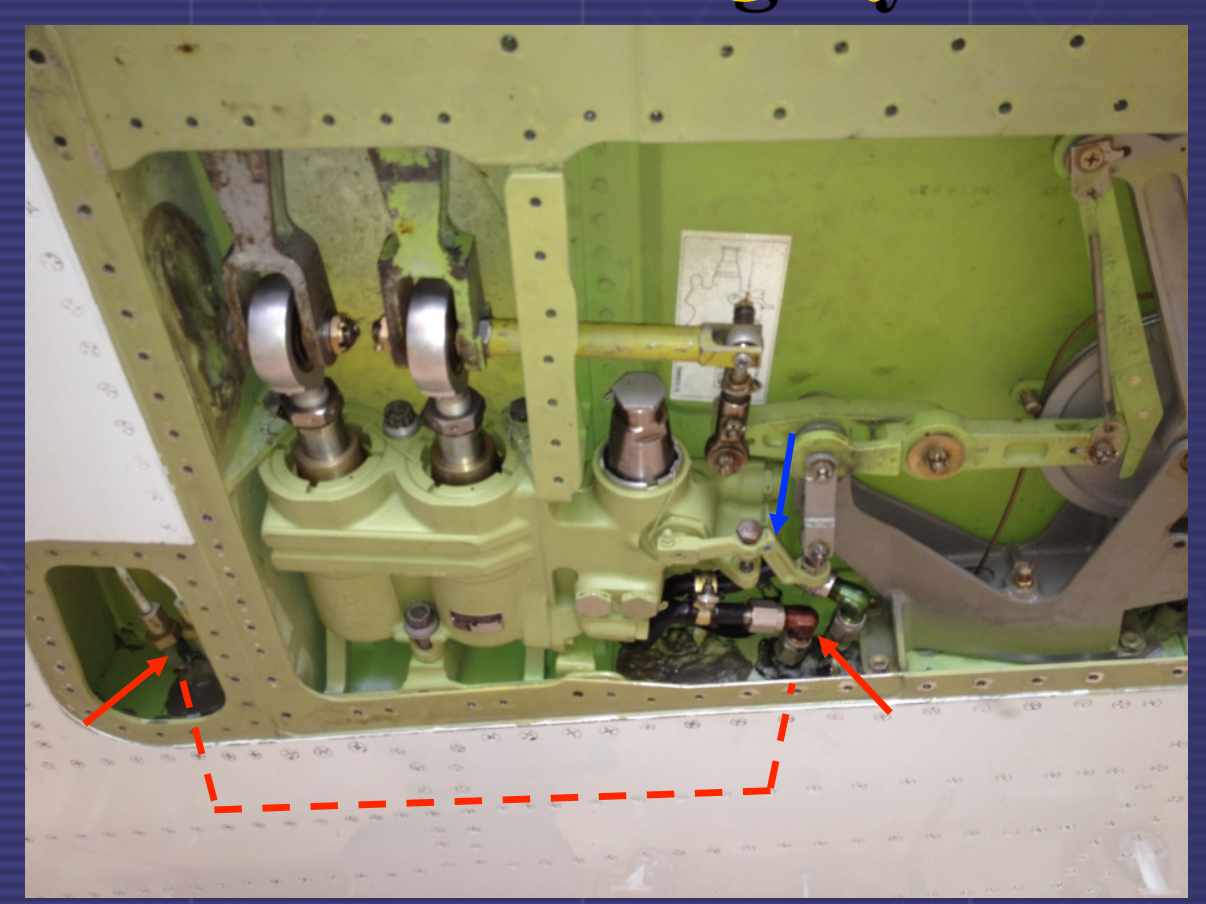

Fittings from failed tubing can be seen (red arrows). The majority of tubing lies fore within a different panel not visible in view. Dotted lines represent failed tubing position.
Underside view of starboard wing showing hydraulic aileron actuator system.

The blue arrow points to blue dot indicating lever passed inspection. This lever was responsible for the accident resulting in fatal injuries to Air Force Major Blair Faulkner and $2^{\text {nd }}$ Lt. Matthew Emmons during take-off from Columbus AFB Miss on 23 April 2008. Mechanical damage caused by fatigue resulted in an uncommanded roll to the left ${ }^{3}$.

NASA Astronaut Clifton Curtis Williams was killed 05 October 1967 near Tallahassee, FL when his plane went into an uncontrollable aileron roll. 


\section{ENGINEERING HUINAN EPACEFI_IGHT}

\section{A EA ENGEERRMG DIRECTORATE}

\section{Burst Hydraulic Alieron Return Line:}
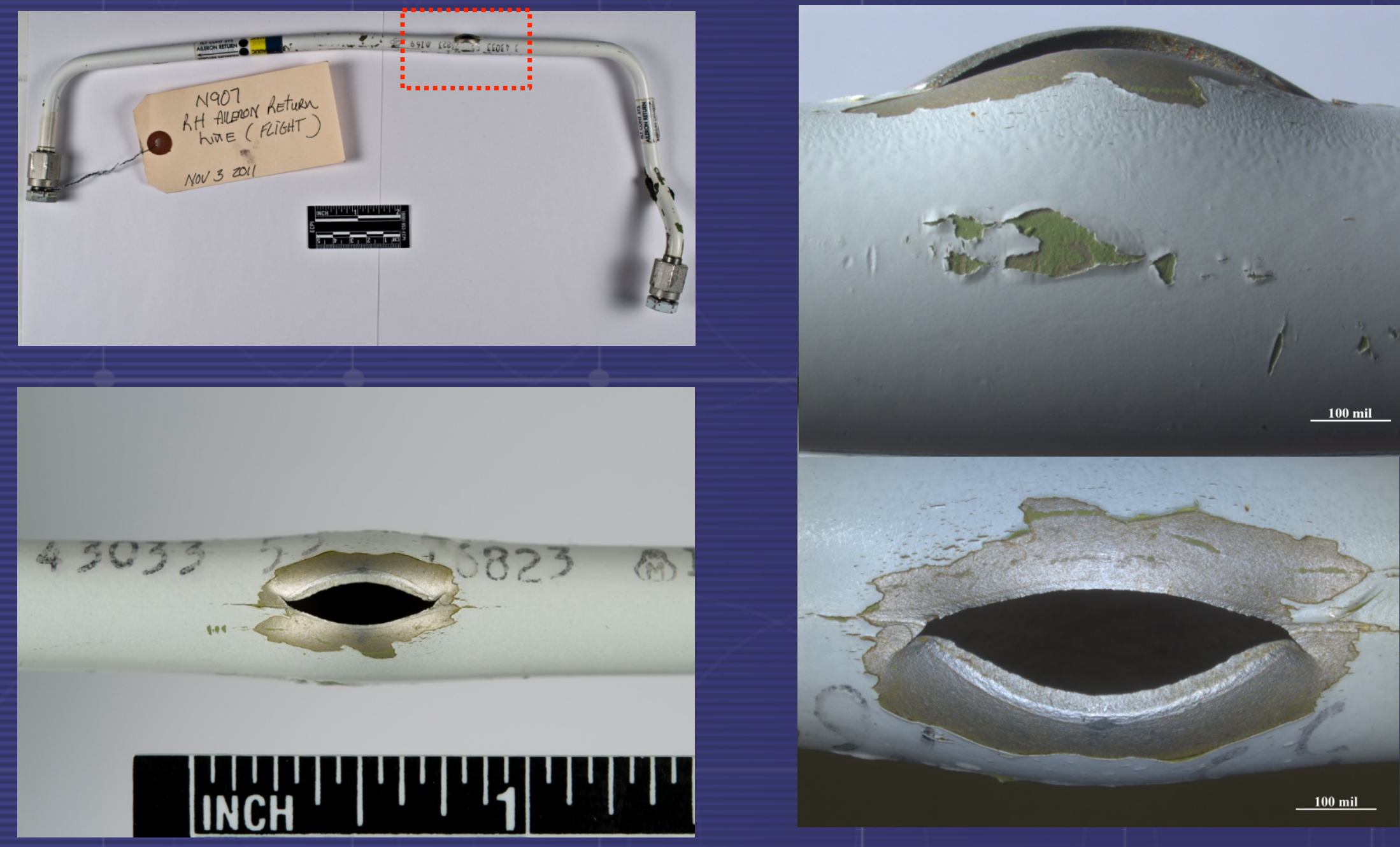

100 mil

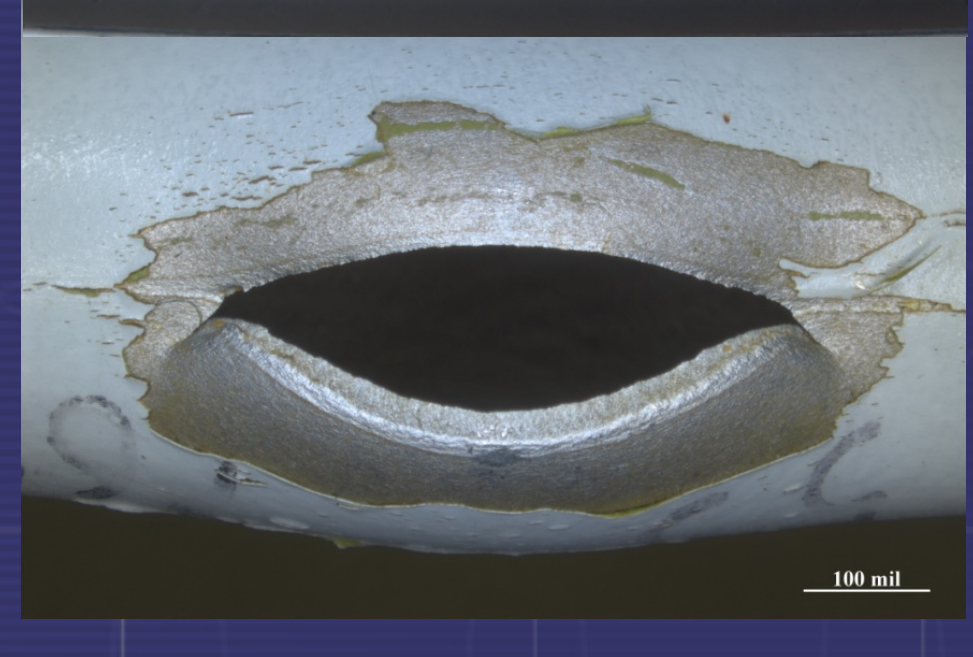

NATIONAL AERONAUTICS 


\section{Fractography:}

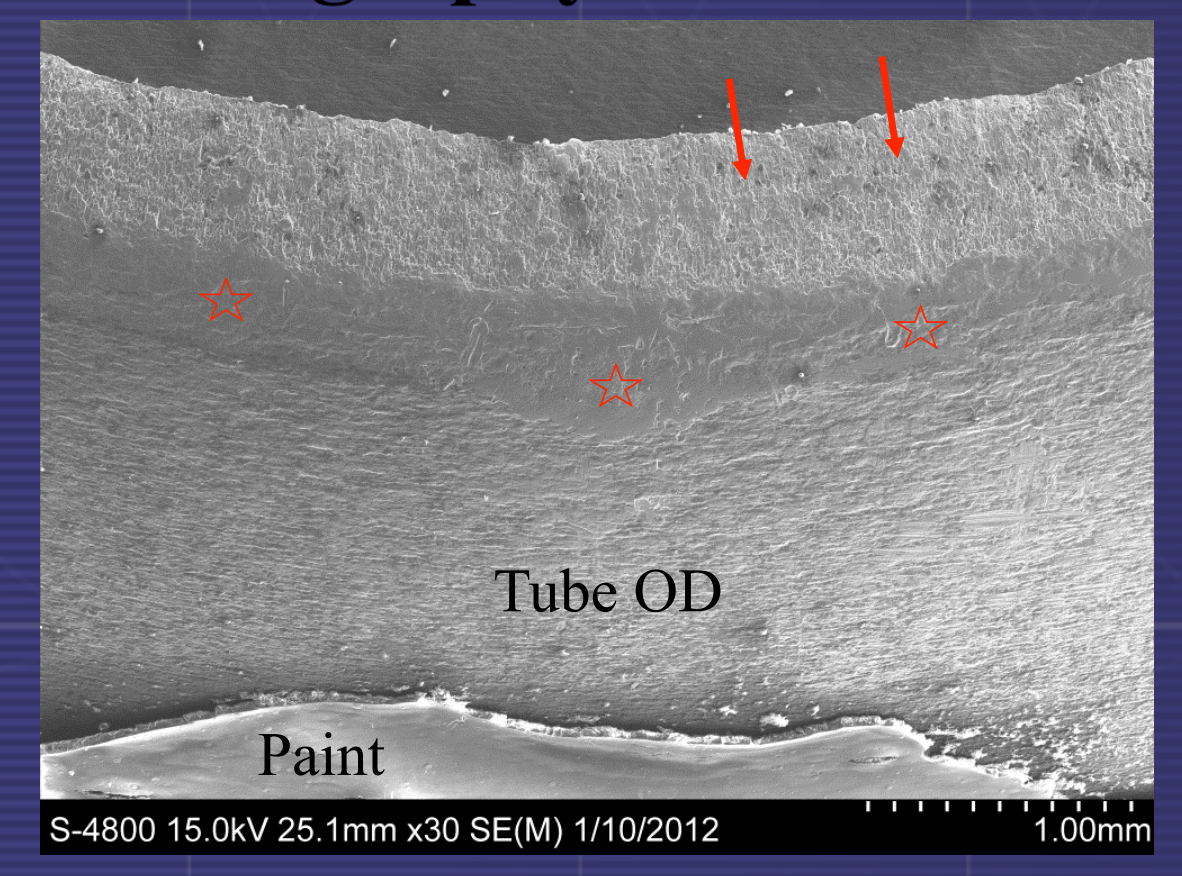

Ratchet marks are observed on the ID (black arrows), indicating high local stress and multiple stack initiation sites on different planes.
Fracture surface has some crack arrest bands (red arrows) originating on the tube ID. Multiple site arrest bands are semi-circular in shape with radii originating in the center of tube. Shear lip (red stars) is noted near the tube OD.

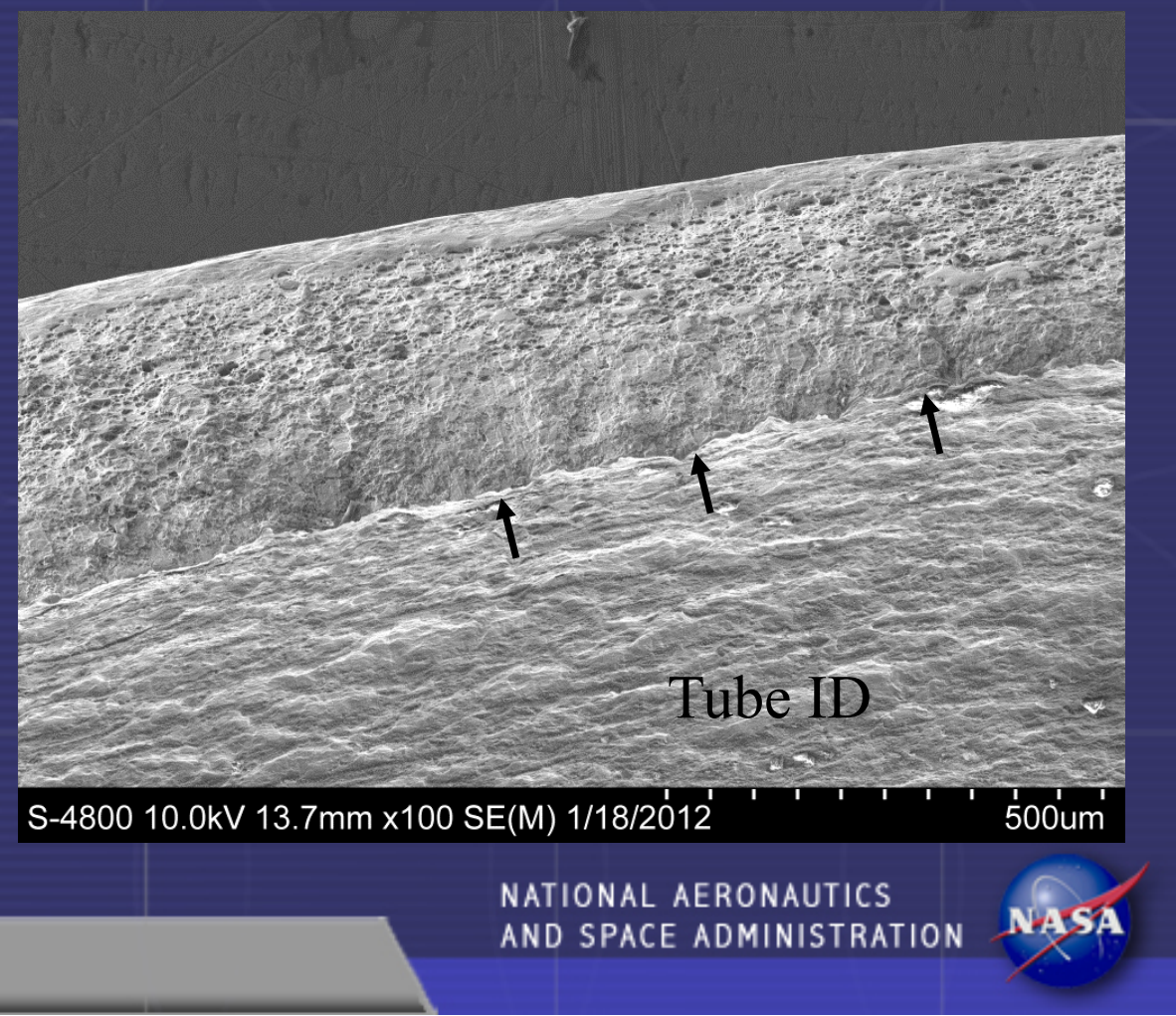




\section{Fractography:}

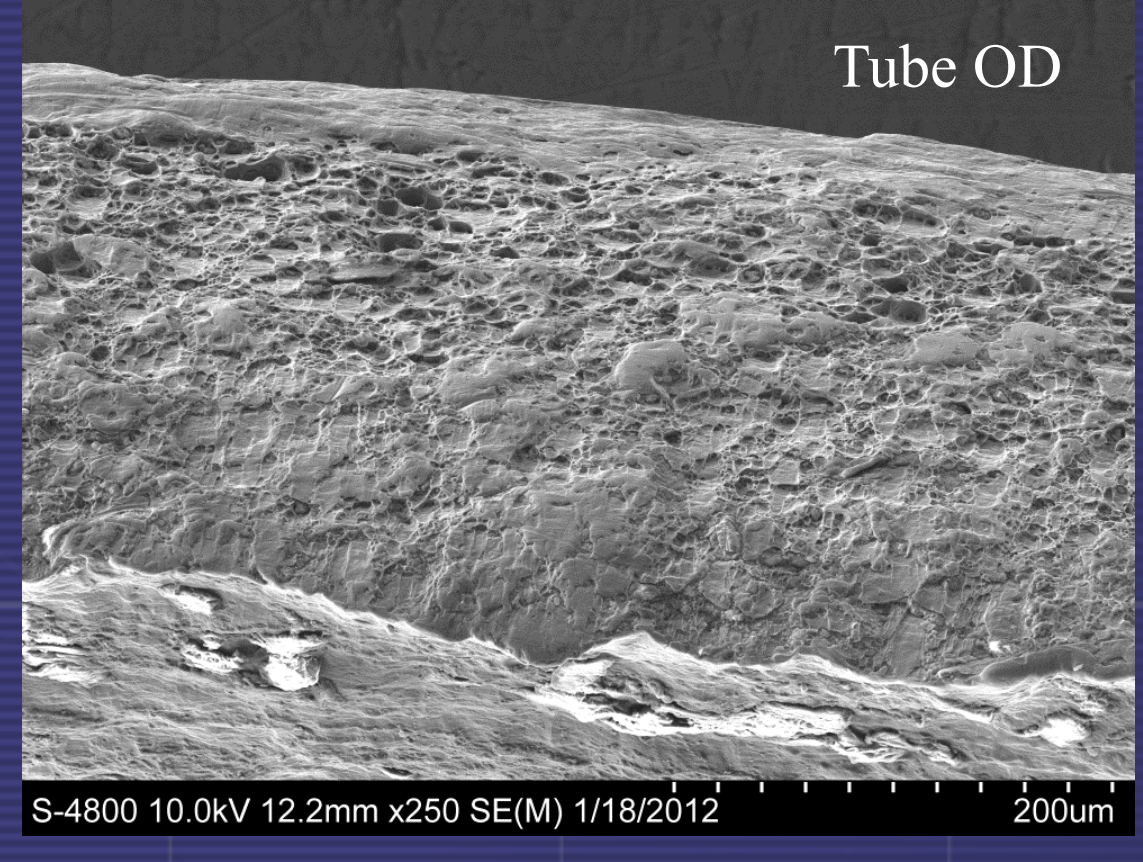

Ductile dimple mode fracture adjacent to cleavage facets indicate a high level of stress (above the yield strength) at the origin surface.
Tear ridges originate on the tube ID and progress towards the OD.

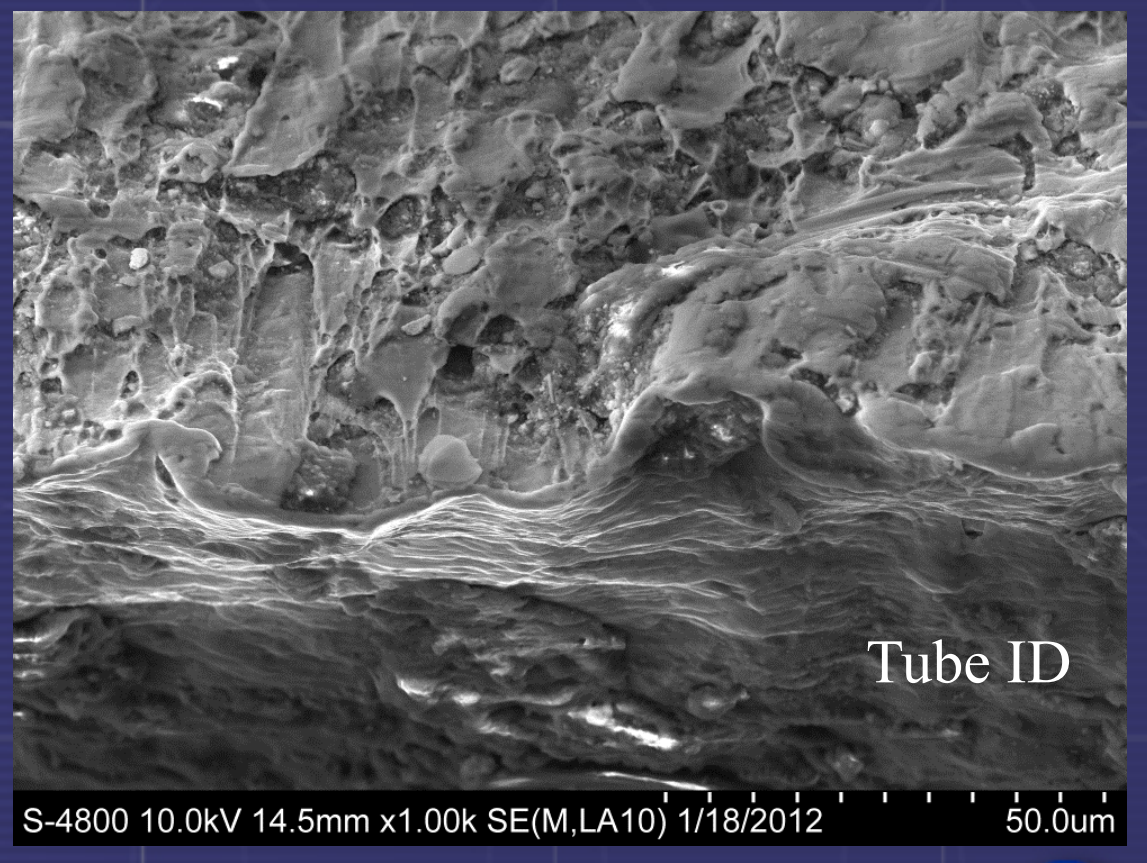

NATIONAL AERONAUTICS AND SPACE ADMINISTRATION 


\section{Dimensional Analysis of Wall Thickness:}

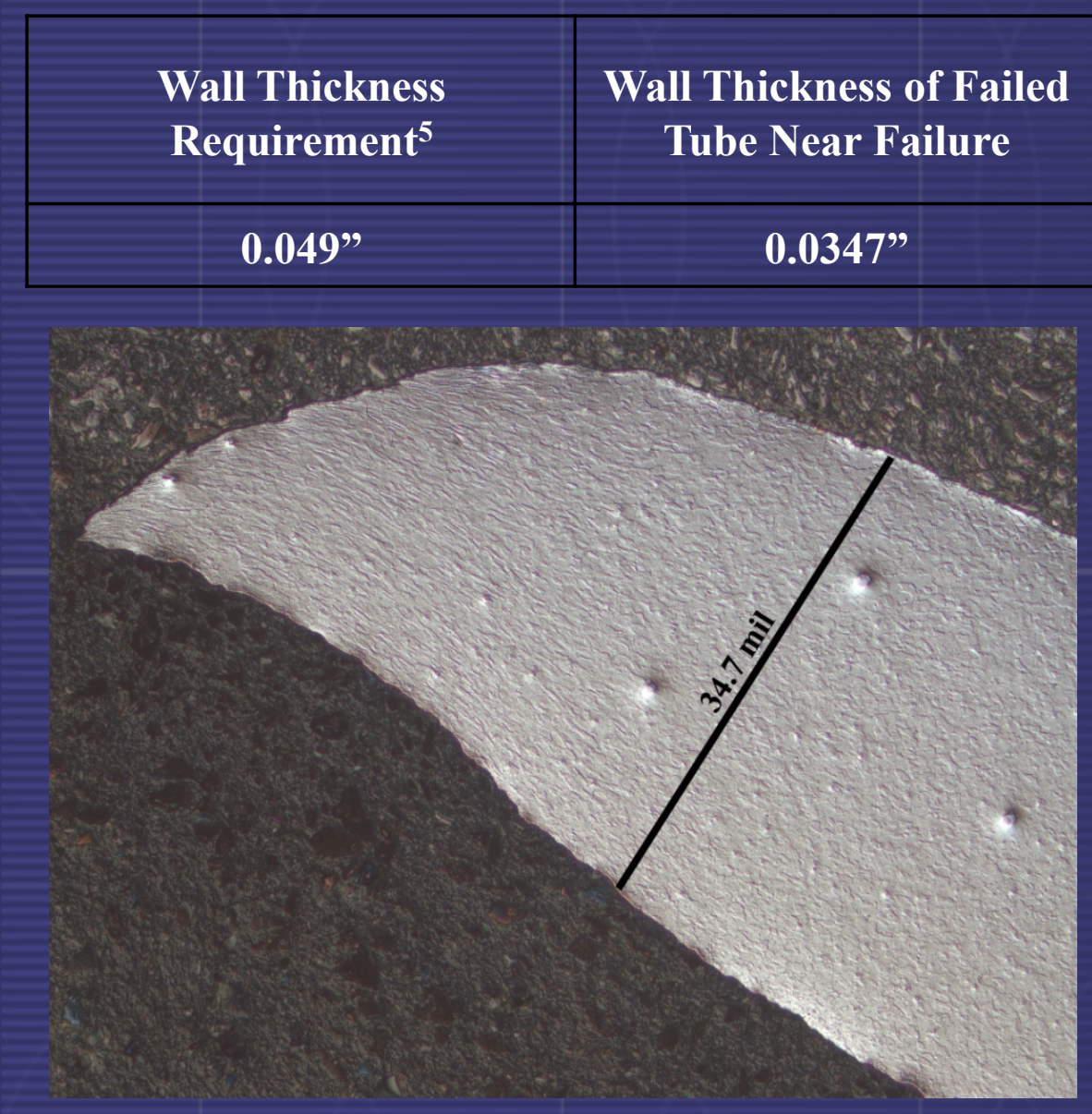

Failed Tube Near Point of Failure
Wall Thickness of Failed Tube $\quad$ Replacement Tubing
Away from Failure

$0.0454 \%$

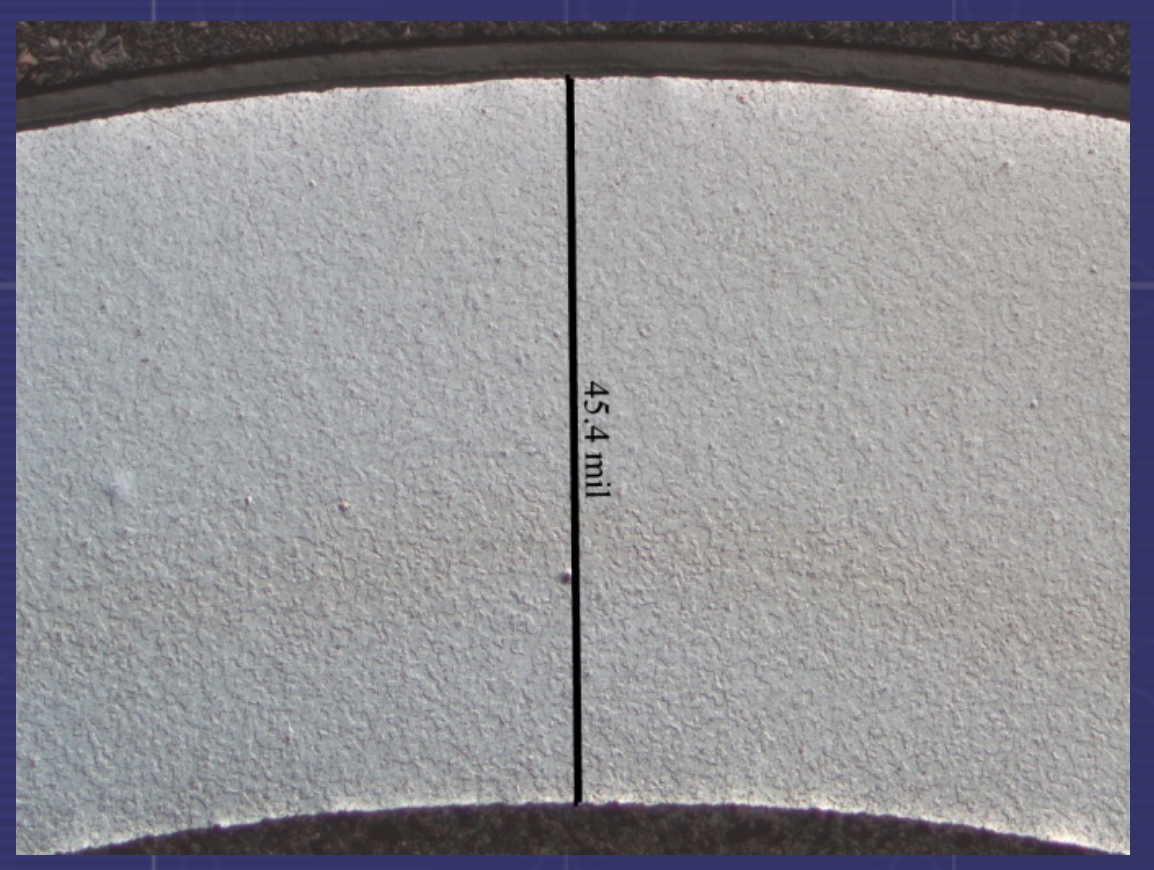

Failed Tube Away From Failure 


\section{Metallography of Fracture Origin:}
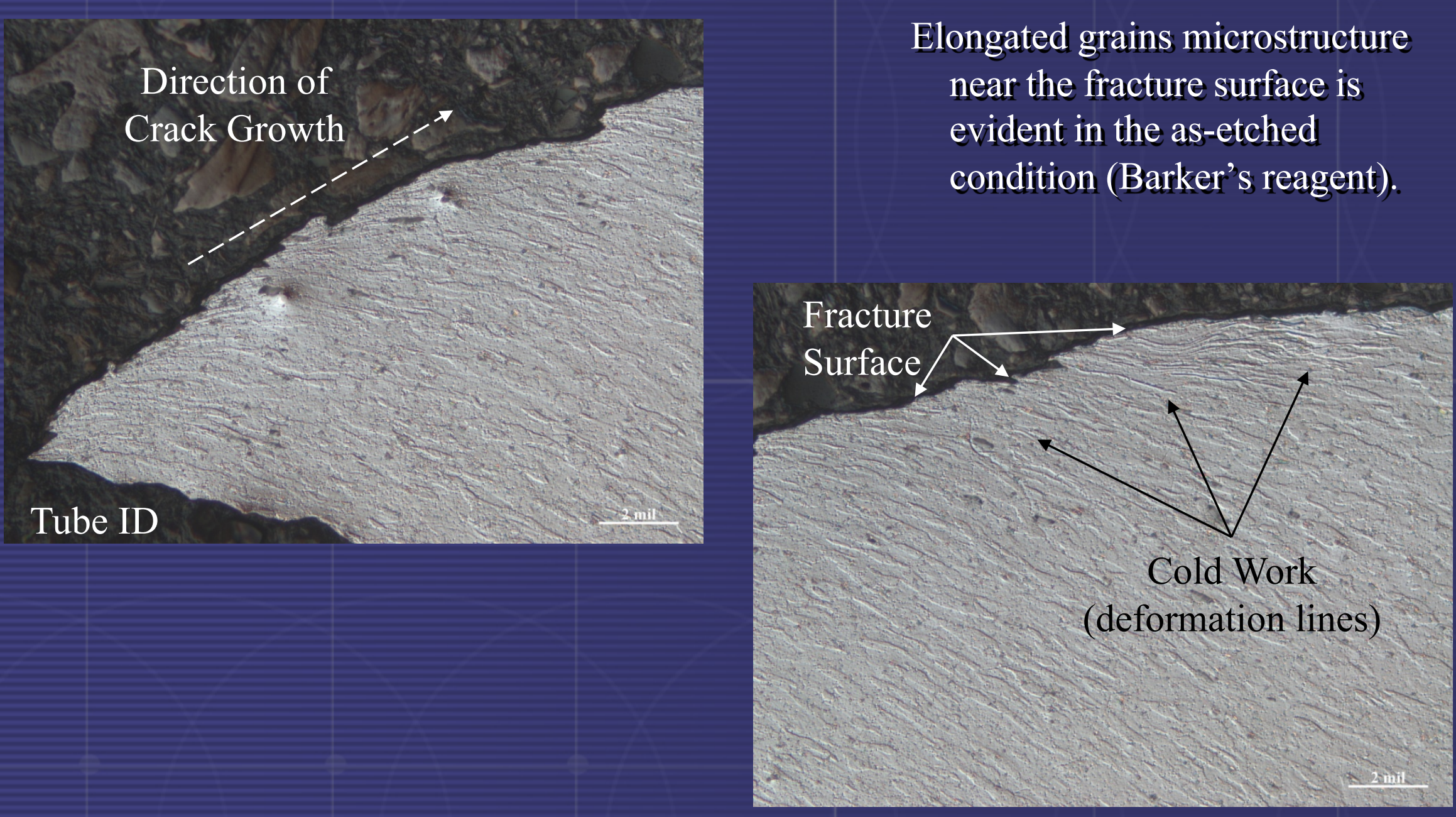


\section{Stress Analysis:}

Assuming a straight tube section remote from any geometrical stress concentration features the stresses associated from only internal pressure loading for a thin wall tube are given by the following relationship. The thin wall formulation assumes a uniformly distributed stress over the wall thickness and is valid only for geometric sections such that $\mathrm{R} / \mathrm{t} \geqslant 10$.
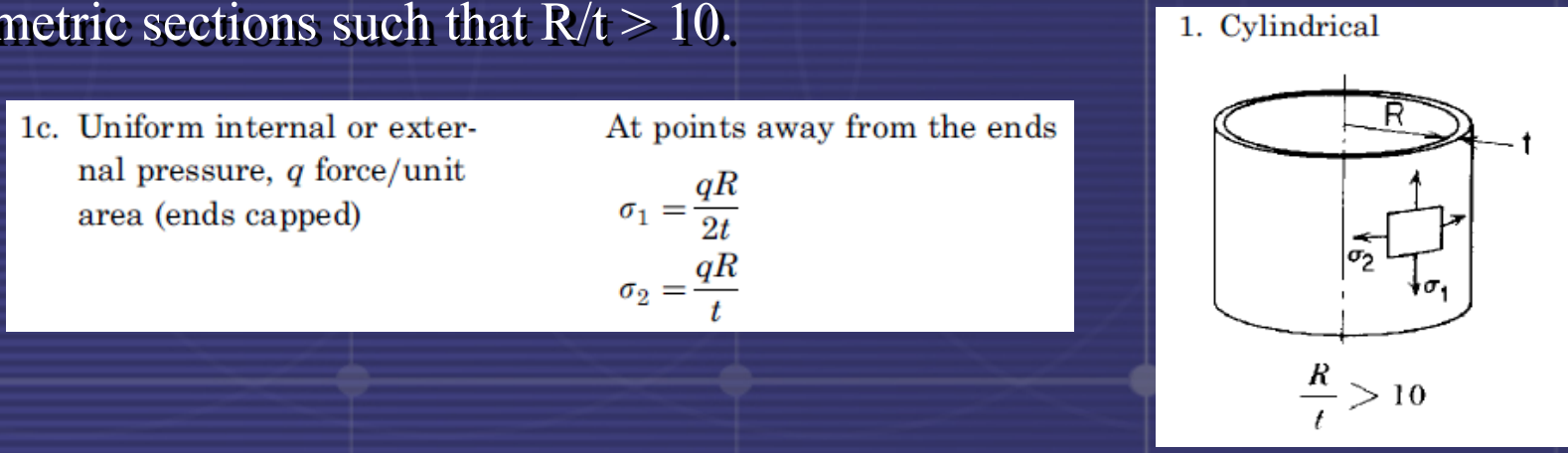

If the tube geometry is such that $\mathrm{R} / \mathrm{t}<10$ then the thick wall cylinder solution is required to accurately characterize the stress distribution over the wall thickness. The stress relationship for a thick wall cylindrical vessel configuration is provided below ( $\sigma_{2}$ defines the hoop stress in the formulation below).

1. Cylindrical disk or shell

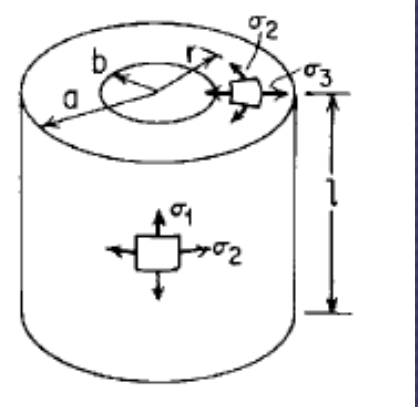

For a $3 / 8^{23}$ tube with a wall thickness of 0.049 "' the ratio of the inside radius to wall thickness is 2.8 which is less than required 10 or more ratio.

1a. Uniform internal radial pressure $q$, longitudinal pressure zero or externally balanced; for a disk or a shell

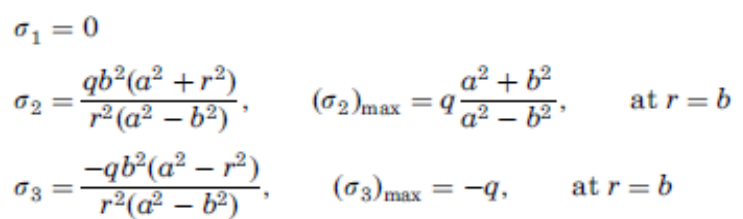




\section{Stress Analysis:}

The thin and thick wall peak stress result for a unit internal pressure of 1,000 psi is 2.826 and $3.401 \mathrm{ksi}$ respectively. A plot of the thin and thick wall stress distribution for the unit pressure load of 1,000 psi is provided below:
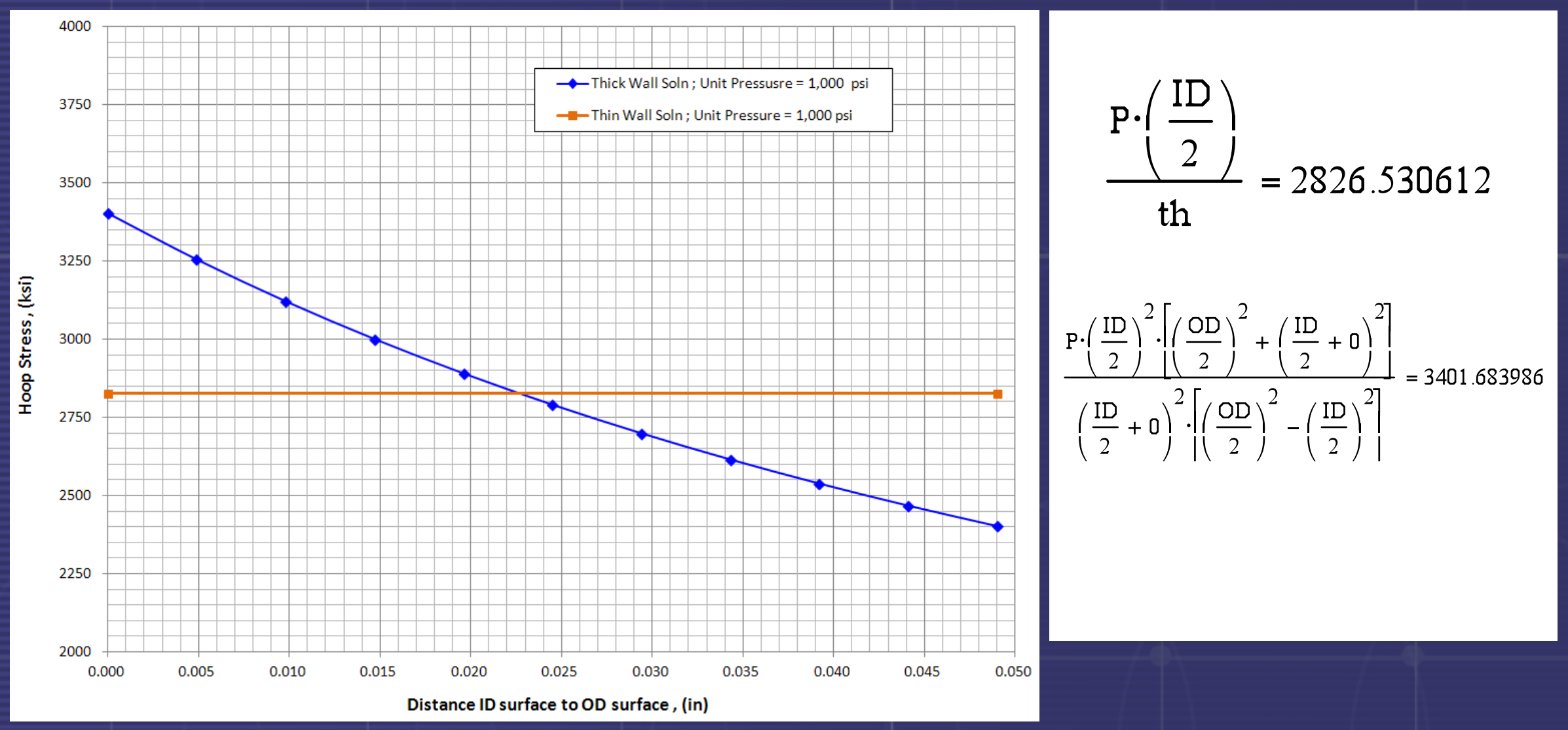


\section{Stress Analysis:}

The pressure failure load for a $3 / 8$ " OD tube with a wall thickness of 0.049 " is projected analytically. An elastic perfectly-plastic material response is assumed using the average of the yield (13 ksi) and ultimate (28 ksi) material allowables; (flow/yield stress $=20.5 \mathrm{ksi}$ ). A net section collapse is utilized as the failure criterion (no stress concentrations and thus no steep gradients present which typically justify incorporating a strain-to-failure exceedance). At 6,500 psi the flow stress almost fully consumes the tube section and analytical convergence at 7,000 psi was not possible.

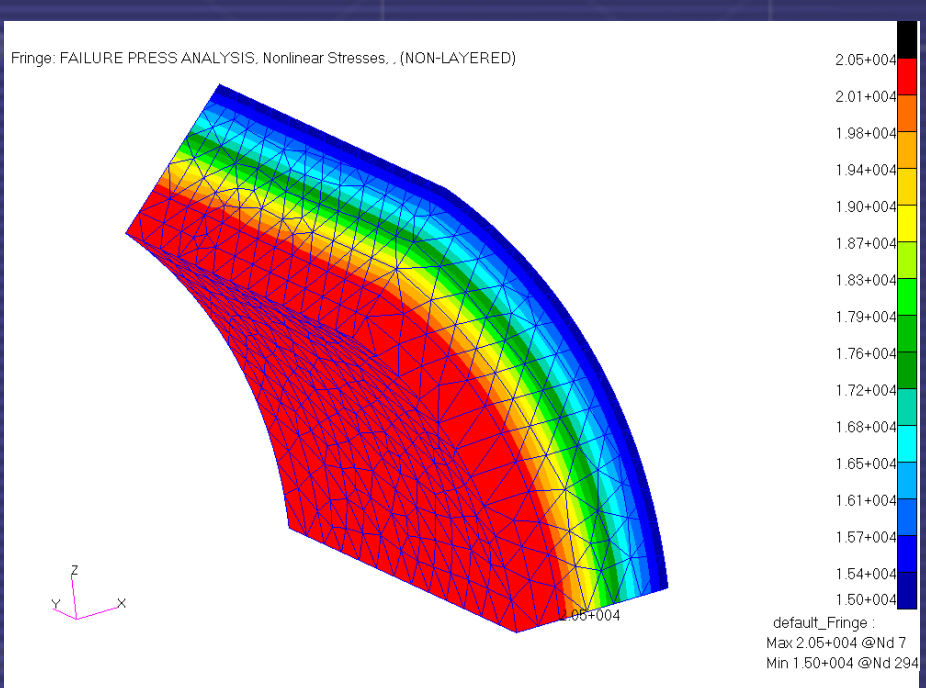

6,000 psi internal pressure nonlinear stress distribution $\mathrm{OD}=3 / 8$ " Th=0.049"

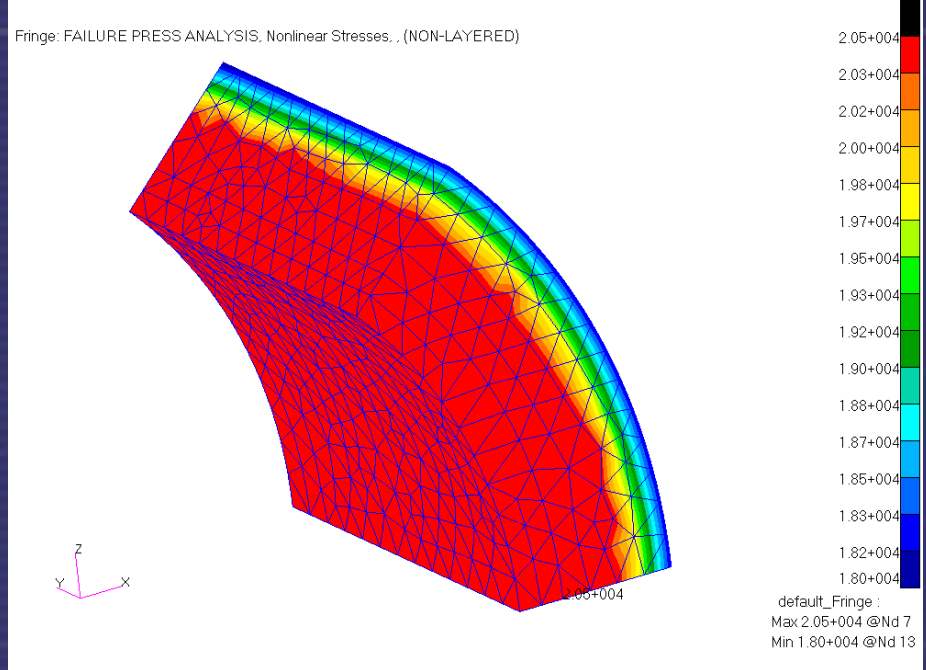

6,500 psi internal pressure nonlinear stress distribution $\mathrm{OD}=3 / 8 " \mathrm{Th}=0.049 "$ 


\section{Stress Analysis:}

The pressure failure load for a $3 / 8$ " OD tube with a wall thickness of 0.035 " is projected analytically. An elastic perfectly-plastic material response is assumed using the average of the yield (13 ksi) and ultimate (28 ksi) material allowables; (flow/yield stress $=20.5 \mathrm{ksi}$ ). A net section collapse is utilized as the failure criterion (no stress concentrations and thus no steep gradients present which typically justify incorporating a strain-to-failure exceedance). At 4,250 psi the flow stress almost fully consumes the tube section and analytical convergence at 4,500 psi was not possible.
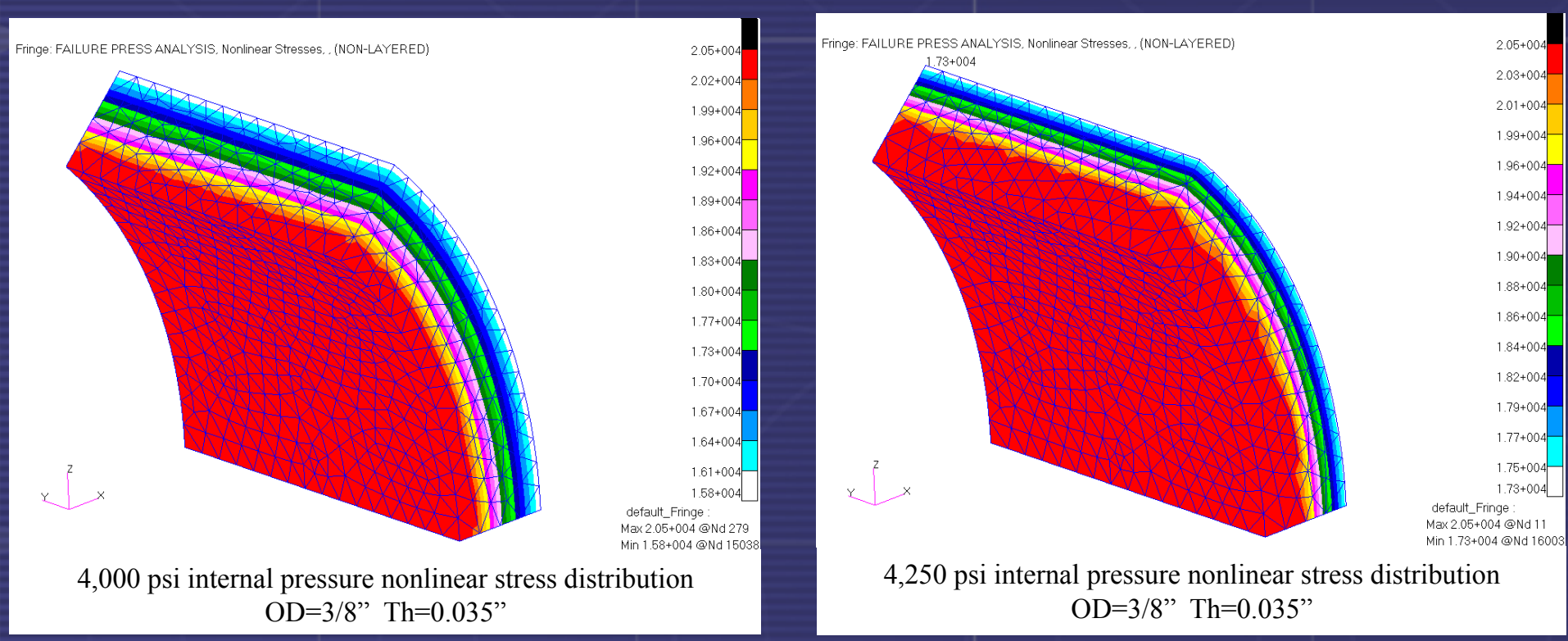

4,250 psi internal pressure nonlinear stress distribution $\mathrm{OD}=3 / 8 " \mathrm{Th}=0.035 "$ 
ENGINEERING HUNAN SPAEEFILIEHT

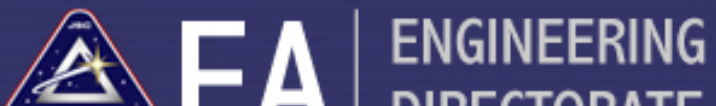 DIRECTORATE}

\section{Optical Emission Spectroscopy (OES):}

\begin{tabular}{|c|c|c|}
\hline \multicolumn{2}{|c|}{ Chemical Composition Requirement $^{6}$} & $\underline{\text { OES Test Results }}$ \\
\hline$\underline{\text { Element }}$ & $\underline{\text { Percent }^{-}}$ & $\underline{\text { Percent }}$ \\
\hline Magnesium & $2.2-2.8 \%$ & $2.24 \%$ \\
\hline Chromium & $0.15-0.35 \%$ & $0.21 \%$ \\
\hline Iron plus Silicon & $0.0-0.45 \%$ & $0.29 \%$ \\
\hline Manganese & $0.0-0.10 \%$ & $0.01 \%$ \\
\hline Copper & $0.0-0.10 \%$ & $0.03 \%$ \\
\hline Zinc & $0.0-0.10 \%$ & $0.01 \%$ \\
\hline Aluminum & Remainder & $96.39 \%$ \\
\hline
\end{tabular}




\section{Summary of Observations:}

- Crack arrest bands were observed at low magnification originating on the ID.

- Ductile dimple mode fracture is observed on the tube fractures.

- Cleavage facets and ductile dimple mode fracture are observed in the fracture initiating at the tube ID.

- The unetched cross-section reveals thinning in the burst region.

- The etched microstructure reveals work-hardening in the necking region. 


\section{Summary of Observations:}

- The nominal thickness of the tube (away from the burst) measured $30 \%$ below specification.

- OES confirms the hydraulic tube is made of the correct material (5052 Aluminum).

- Conductivity confirms the hydraulic tube is in the annealed condition, 36\% International Annealed Copper Standard (IACS).

- The hardness tested slightly above (77 HRE) the maximum hardness (70 HRE) for 5052-0. 


\section{Conclusions:}

- The hydraulic tube failed from high stress, low-cycle fatigue (LCF) initiated on the tube ID and progressed to the OD (shear lip).

- Crack arrest bands indicate the failure took several cycles to fail.

- The fracture exhibits predominant shear dimples which are characteristic of high load ductile fractures.

- Distortion and wall thickness reduction during failure also indicate very high loads. 


\section{Conclusions:}

- Based on the tube microstructure through the burst, it is likely that the initial wall thickness was about 0.035 " rather than the requirement of $0.0499^{3}$.

- The wall thickness was approximately $30 \%$ thinner than required. Plastic deformation and thinning of the out-ofspecification tube wall likely occurred during the initial proof testing many years ago. 